\title{
O RESGATE DO DIREITO DAS TRABALHADORAS GESTANTES: O TRABALHO INTERDISCIPLINAR DO PET SAÚDE NO SISTEMA ÚNICO DE SAÚDE
}

\author{
Renata Campos \\ Luciana Maria Mazon \\ Jessica Seredniski Melnek \\ Jessica da Silva Melo \\ Geisa Carla Wendt Kraschinski \\ Geise Patricia Henrique de Melo \\ Mariani Ribas Oldoni \\ Carla Tatiane do Amaral Dallago \\ Marcio Siefert \\ Marlon Cesar Benda \\ Heloisa Schelbauer Dzickanski \\ Guilherme Douglas Piel Dornelles \\ Luiz Eduardo Becker \\ Universidade do Contestado - UnC. Mafra, Brasil \\ Adriana Moro Wieczorkievicz \\ Secretaria Municipal de Saúde de Mafra \\ Universidade do Contestado - UnC. Mafra, Brasil \\ Araci Gelbcke Wielewski \\ Keli Vanessa Poltronieri \\ Talita Cristina de Almeida Schmidt \\ Francesli Patricia Pereira Heilmann
}

Secretaria Municipal de Saúde de Mafra. Mafra, Brasil

\begin{abstract}
Resumo. O objetivo deste estudo foi conhecer o perfil das mulheres gestantes trabalhadoras. Esta pesquisa foi de natureza transversal e prospectiva, com abordagem quantitativa. Foram estudadas 187 gestantes, com idade de 27,11 +5,9 anos. Utilizou-se um questionário abordando dados gerais, hábitos de vida, condição no mercado de trabalho e entendimento sobre direitos trabalhistas. $32,1 \%$ das gestantes são agricultoras, 58\% assalariadas e 52,9\% conhecem seus direitos. 99,5\% relataram ter autorização do empregador para realizar o pré-natal. Em 41,7\% dos casos houve troca da função laboral. Foram realizadas oficinas sobre direitos da gestante ministradas por um docente do curso de Direito. Conclui-se que as gestantes têm acesso ao sistema de saúde e que a integração com os profissionais da rede, equipe PET e os participantes do curso de direito permitiram um novo olhar para a educação em saúde.
\end{abstract}

Palavras-chave: Gestante, Trabalho, Direito, Saúde. 


\title{
THE RIGHTS OF PREGNANT WOMEN WORKERS: THE INTERDISCIPLINARY PET HEALTH GROUP IN HEALTH CARE SYSTEM
}

\begin{abstract}
The aim of this study was to understand the profile of pregnant working women. This study was a cross-section survey with a quantitative approach. There were included 187 pregnant women with $27.11 \pm 5.9$ years old. A questionnaire with general data, lifestyle habits, working condition, and knowledge about the of labor rights was used. $32.1 \%$ of pregnant women are farmers and $52.9 \%$ know their rights. The $99.5 \%$ of the women have employer's permission to perform maternity leave, in $41.7 \%$ of the cases there was an exchange of working function. Workshops about the rights of pregnant women were performed by a teacher of a law school. We conclude that pregnant women have access to the health system and that the integration with network professionals, the PET health group, and the law course allowed them to get a new vision of health and education.
\end{abstract}

Keywords: Pregance, Work, Right Working, Health.

\section{RESCATE DE LOS TRABAJADORES DERECHOS DE LAS MUJERES EMBARAZADAS: EL TRABAJO INTERDISCIPLINARIO DE PET SALUD EN SISTEMA DE ATENCIÓN DE LA SALUD}

Resumen. El objetivo de este estudio fue conocer el perfil de las trabajadoras embarazadas. Este estudio fue transversal y la naturaleza prospectiva con enfoque cuantitativo. Se estudiaron 187 mujeres embarazadas de 27,11 \pm 5,9 años. Se utilizó un cuestionario sobre datos generales, estilo de vida, el estado del mercado laboral, y la comprensión de los derechos laborales. El 32,1\% de las mujeres embarazadas son agricultoras, el 52,9\% conoce sus derechos. El 99,5\% reportó tener la autorización del empleador para la baja maternal, en el $41,7 \%$ de los casos se produjo un intercambio de la función de la mano de obra. Se realizaron talleres sobre los derechos de las mujeres embarazadas dadas por un profesor de la escuela de derecho. Se concluye que las mujeres embarazadas tienen acceso a la atención sanitaria y que la integración con los profesionales de la red, el equipo PET y el curso de derecho inculcaron una nueva visión sobre la educación y la salud en las participantes.

Palabras clave: Embarazo, Trabajo, Derecho, Salud.

\section{Introdução}

A inserção do Programa de Educação pelo Trabalho para a Saúde (PET) trouxe uma nova perspectiva de aproximação entre Instituição de Ensino Superior (IES) e sistema de saúde, socialmente orientada, comprometida e ampliada para a saúde, com foco na atenção primária. O PET Saúde tem suas ações direcionadas para o fortalecimento de áreas estratégicas para o SUS, de acordo com a Portaria Interministerial $n^{\circ} 421$, de 03 de março de 2010, disponibilizando bolsas como incentivo ao estudo e à produção científica (Brasil, 2011). As ações do PET Saúde vão ao encontro do grande desafio de desenvolver a autonomia individual em íntima coalizão 
com o coletivo, na busca da construção de redes de mudanças sociais, com a consequente expansão da consciência individual e coletiva (Mitre e outros, 2008).

A Universidade do Contestado (UnC) implementou o Programa PET saúde com ênfase no fortalecimento da rede de atenção aos trabalhadores em três municípios da $25^{\circ}$ Secretaria de Desenvolvimento Regional de Santa Catarina (Mafra, Itaiópolis e Papanduva). Várias ações foram propostas pelo PET na atenção primária, e as experiências dos alunos junto aos atendimentos e experiências do Sistema Único de Saúde - SUS, no campo do cuidado à saúde da mulher, trouxeram uma realidade que foi de imediato diagnosticada, o limitado acesso das gestantes trabalhadoras aos serviços de saúde, bem como as limitadas informações quanto aos seus direitos trabalhistas no período gestacional.

A situação diagnosticada pelos alunos em campo trouxe duas reflexões acerca da temática da saúde da mulher trabalhadora e gestante. A primeira vem de uma reflexão da perspectiva de que o trabalho em nossa sociedade aparece imbuído de uma conotação negativa, pela precariedade de sua execução e falta de políticas públicas eficazes em torno dele. Na realidade, o trabalhador vende sua força de trabalho, o que pode resultar em sofrimento e desgaste físico e mental. A segunda diz respeito a perspectiva feminina desse fato, que se apresenta de forma ainda mais inflexível, apontando a invisibilidade social do trabalho produtivo da mulher e uma divisão sexual do trabalho, conforme dissertou Oliveira (2001).

A despeito das inegáveis melhorias observadas no sistema de saúde do Brasil no período posterior à Constituição Federal de 1988, e após o processo de descentralização, pode-se dizer que muito há que ser feito, principalmente no que diz respeito à redefinição de modelos de atenção, da melhoria e qualidade de gestão dos serviços saúde (Brasil, 2005). Nesse contexto, embora melhorias sejam notadas também no campo da saúde do trabalhador, observa-se que as ações destinadas as trabalhadoras gestantes ainda se dão de forma isolada, fragmentada e desigual nos estados e municípios brasileiros.

Essa desarticulação pode ter vários determinantes: lacunas assistenciais; baixa eficiência no uso de recursos, deficiência na integralidade e modelos inadequados de atenção à saúde. Esses fatores têm contribuído para o atraso no cumprimento constitucional, previstos para as ações na saúde do trabalhador no SUS e reflete o aumento da gravidade dos acidentes de trabalho.

As condições relacionadas ao sexo foram trazidas para a discussão, tanto na saúde reprodutiva como um todo, mas, principalmente, na condição da 'maternidade', que ainda é uma situação que dificulta a permanência da mulher no mercado de trabalho, pois muitos empregadores as observam como algo negativo, devido ao aumento de custos pela utilização dos benefícios trabalhistas, bem como a diminuição da produtividade. Torna-se evidente, já nos primeiros meses de gestação, as alterações fisiológicas e anatômicas, o que trazem mudanças significativas no organismo materno. 
Muitas mudanças iniciam-se desde o momento da nidação, que ocorre em um tempo médio de sete dias após a fecundação do óvulo e se estendem até o final da gestação (Souza, Filho e Ferreira, 2002).

As características da divisão sexual do trabalho e as discussões de gênero nos fazem refletir sobre uma desigualdade na incorporação das mulheres ao trabalho assalariado, não resultando numa redistribuição do trabalho doméstico. A mulher assumiu cargos produtivos assalariados, mas também, ficou com a responsabilidade do cuidado da casa e dos filhos. A mulher continuou com esse papel, independentemente de assumir outro tipo de trabalho, cujo poder de barganha é reduzido pela estrutura do mercado, que oferece menos alternativas às mulheres (Oliveira, 2001).

Além disso, no que concerne ao direito das trabalhadoras, o modelo de previdência social adotado no Brasil traz distinções importantes entre trabalhadoras do meio urbano e rural. Para o setor urbano, cujos trabalhadores de um modo geral têm empregos assalariados formais e rendimentos regulares, não pode ser aplicado ao setor rural, no qual os trabalhadores não contam com rendimentos regulares nem se classificam de modo geral como assalariados (Brumer, 2002). Há de ressaltar as desigualdades de acesso à saúde, embora a situação dos trabalhadores das zonas urbanas seja preocupante, devemos observar as frágeis ações de atenção à saúde do trabalhador rural, que faz com que essa população encontre dificuldades significativas de acesso às ações do SUS, um alerta preocupante para as gestantes trabalhadoras.

Segundo Brito e D'acri (1991) a saúde das mulheres trabalhadoras pode ser identificada como uma temática de investigação indispensável para o enriquecimento do campo de estudos na relação saúde/trabalho, uma vez que homens e mulheres são expostos a condições de trabalho diferenciadas no processo produtivo.

A saúde das mulheres e sua relação com o trabalho conta com um impacto diferencial pela concentração de empregos precários, devido a sub valorização e exposição a múltiplos riscos. Assim como, outros riscos considerados como invisíveis por Dejours (1992), às características atribuídas socialmente ao gênero feminino, como docilidade, compromisso, entrega, e outros que são identificados pelos empregadores, como condições ideais de baixa sindicalização, intensificação da jornada de trabalho e afetam de forma diferenciada a saúde das mulheres trabalhadoras pela inserção laboral própria. No cenário atual, a mulher contribui para a renda familiar e, dessa forma, para o desenvolvimento das comunidades, como empresária agrícola ou não, em empresas familiares, asssalariadas ou autônomas; e ainda assim são responsáveis por uma quantidade desigual de trabalho doméstico não remunerado (International Labour Office, 2012).

Dessa forma, se a deterioração das condições e relações de trabalho atinge o conjunto dos trabalhadores, ela incide de forma especial e mais aguda sobre as mulheres trabalhadoras, pois no seu caso, as novas formas de exclusão se sobrepõem aos antigos mecanismos de exclusão de gênero, potencializando-os. O impacto deste trabalho tem 
uma interferência decisiva na vida pessoal e profissional das mulheres, afetando sua saúde, sobretudo pela configuração de uma dupla jornada de trabalho (Oliveira, 2001) e muito mais além na situação da gestação.

Brito (1996) refere que as doenças associadas ao trabalho se caracterizam por serem do tipo insidiosa, inespecífica e indenizável, sem normas apropriadas às condições do trabalho feminino. Nos países onde há uma concentração de mulheres pobres, o risco à saúde pode se apresentar maior, sobretudo pela restrição do acesso aos serviços básico, o que pode ser visualizado pelos alunos em muitas situações do projeto PRO-PET.

Destaca-se, ainda, que as mulheres/mães caracterizadas por precárias condições econômicas e sociais, podem não dispor de recursos para cuidar de sua própria saúde. A oferta ampliada de mão de obra nas atividades informais favorece a ocupação de cada uma nos espaços urbanos, sem infraestrutura adequada, apresentando cada vez mais um risco à saúde. Nesse sentido, pensar os efeitos do trabalho sobre saúde da mulher pobre requer pensá-la como um processo, sobretudo pelas diferentes circunstâncias sociais e econômicas em distintas culturas (Anderson, 1994).

Quando se aponta toda a problemática que cerca a relação de trabalho e da mulher, temos alguns documentos, como o da Organização Internacional do Trabalho, que é clara quanto aos direitos das mulheres no que se refere à estabilidade de emprego, licença, gestação/maternidade remunerada, creche e pausas regulamentadas para amamentação (Godoy, Gomes, Stefanello, Monteiro e Nakano, 2011), mesmo assim, parece à legislação um tanto distante do conhecimento da realidade.

Reitera-se que a Política Nacional de Saúde do Trabalhador e da Trabalhadora (PNST) (Brasil, 2012), recentemente instituída, também faz menção aos direitos das gestantes e nutrizes trabalhadoras, à assistência de saúde e condições adequadas de trabalho, corroboradas pela nossa legislação, por meio da Consolidação das Leis de Trabalho (CLT), que garante proteção aos direitos trabalhistas em prol da saúde das gestantes e do lactente.

Apesar da PNST estar em vigor, e objetivar o desenvolvimento da atenção integral à saúde do trabalhador, com ênfase na vigilância, visando a promoção e a proteção da saúde dos trabalhadores e a redução da morbimortalidade decorrente dos modelos de desenvolvimento e dos processos produtivos, não há até o momento estudos que demonstrem o grau de implantação e sustentabilidade da PNST no País.

Assim, esta pesquisa surgiu de todas essas inquietações relacionadas ao projeto desenvolvido pelo "PRÓ/PET Saúde" com ênfase na aprendizagem que envolve a autoiniciativa, buscando as dimensões afetivas, intelectuais e mudança pelo exercício da curiosidade. As ações básicas deste projeto estiveram voltadas para os trabalhadores das áreas rurais e urbanas, contudo no dia a dia das ações do grupo PET, observou-se que as trabalhadoras, principalmente as gestantes, eram de algum modo negligenciadas em relação aos seus direitos trabalhistas. Diante desta premissa, entende-se ser necessário 
conhecer o perfil das mulheres gestantes trabalhadoras nos municípios da $25^{\circ}$ Secretaria de Desenvolvimento Regional (SDR), bem como o entendimento destas gestantes em relação aos seus direitos trabalhistas.

De fato, a relação entre saúde e o trabalho das mulheres deve ser compreendida dentro de uma complexidade que envolve a singularidade feminina, considerando suas histórias de vida, a importância do trabalho na construção da identidade, o não reconhecimento e a invisibilidade social das características do ambiente, e a organização do trabalho em que estão alocadas durante todo o ciclo de vida que, muitas vezes, intensifica-se na fase adulta reprodutiva.

Por outro lado, mesmo quando homens e mulheres são expostos aos mesmos a riscos iguais, a perspectiva de gênero não é considerada e as mulheres são excluídas das investigações. Ressalta Oliveira (2001) que, há carência de informações sobre os riscos ligados às ocupações e os modos de viver femininos diante das condições de trabalho, considerando as novas formas e novas divisões de trabalho. Sua visibilidade vem se tornando possível com o amadurecimento de estudos e pesquisas sobre a mulher. Neste contexto, o objetivo deste estudo foi conhecer o perfil das mulheres gestantes trabalhadoras.

\section{Método}

A pesquisa foi realizada durante os anos de 2013 e 2014, nos municípios de Mafra, Papanduva e Itaiópolis, municípios que integram a $25^{\circ}$ Secretaria de Desenvolvimento Regional (SDR) do estado de Santa Catarina - Brasil - e que fazem parte do Programa PRÓ/PET Saúde 'Fortalecimento da Rede de Atenção à Saúde do Trabalhador e da Trabalhadora'. O número total da amostra foi de 187 gestantes trabalhadoras, entre o primeiro e o nono mês de gestação, com idade maior ou igual a dezoito anos. Todas as gestantes participantes do estudo concordaram em participar da pesquisa e assinaram o Termo de Consentimento Livre e Esclarecido. Esta pesquisa seguiu todos os preceitos éticos, de acordo com Resolução 466/2012, sob parecer consubstanciado $\mathrm{n}^{\circ} 294.808 / 2013$.

Para a coleta de dados, utilizou-se um questionário semiestruturado, com dados gerais das gestantes, hábitos de vida, situação e condição no mercado de trabalho, bem como se a gestante conhecia seus direitos frente à sua condição. $\mathrm{O}$ questionário foi aplicado em sala reservada nas unidades básicas de saúde dos municípios selecionados, pelos acadêmicos PET dos cursos de Enfermagem, Educação Física, Psicologia, Fisioterapia e Ciências Biológicas.

Em etapa posterior, o grupo PET, baseado nos resultados obtidos, elaborou oficinas sobre os direitos e deveres da gestante para o público-alvo dos três municípios participantes da pesquisa. Essa oficina foi desenvolvida por equipe interdisciplinar, composta por professores do curso de Direito, equipe PET e serviços de saúde. Os 
dados estão expressos por média e desvio padrão e as variáveis categóricas estão descritas em porcentagem.

\section{Resultados}

Essa pesquisa contou com amostra de 187 gestantes, com idade média de 27,11 $\pm 5,9$ anos, com 27,98 $\pm 11,41$ semanas de gestação, sendo 72,2\% da amostra casada, 42,8\% relataram ter Ensino Médio completo e 63,1\% residem na área urbana. Os dados complementares podem ser visualizados na tabela 1 .

Tabela 1. Características sócio demográficas das trabalhadoras gestantes.

\begin{tabular}{|l|r|}
\hline \multicolumn{1}{|c|}{ Variável } & \multicolumn{1}{|c|}{$\%$} \\
\hline Escolaridade & \\
Médio Completo & $42,8 \%$ \\
Fundamental Incompleto & $24,1 \%$ \\
Fundamental Completo & $15 \%$ \\
Superior Completo Incompleto & $3,7 \%$ \\
Superior Completo & $14,4 \%$ \\
\hline Área em que reside & \\
Urbana & $63,1 \%$ \\
Rural & $36,9 \%$ \\
\hline Estado Civil & \\
Solteira & $5,9 \%$ \\
Casada & $72,2 \%$ \\
Viúva & $5,3 \%$ \\
União Marital & $16,6 \%$ \\
\hline
\end{tabular}

Fonte: Autor

Conforme a Tabela 2, a ocupação predominante das gestantes entrevistadas é na agricultura $(32,1 \%), 58,8 \%$ são assalariadas, com carga horária semanal de 41,81 \pm 11,17 horas de trabalho e renda mensal de $\mathrm{R} \$ 1496,97 \pm 825,02$. Nota-se que parcela significativa da amostra relatou saber quais são seus direitos trabalhistas como gestantes (52,9\%). Quando questionadas sobre os riscos laborais, 35,8\% relataram não possuir riscos em seu trabalho. Em $86,1 \%$ dos casos, não houve mudança no comportamento do empregador em relação à gravidez da funcionária e estes dados ratificaram a liberação da gestante pelo empregador, para realizar o pré-natal $(99,5 \%)$. Embora as gestantes tenham seus direitos assegurados quanto à troca de função no trabalho, em virtude da gestação, 57,5\% da amostra relatou que não houve adaptação na atividade laboral. 
Tabela 2. Condições de trabalhos das trabalhadoras gestantes

\begin{tabular}{|l|r|}
\hline \multicolumn{1}{|c|}{ Variável } & \multicolumn{1}{c|}{$\%$} \\
\hline Ocupação & $32,1 \%$ \\
Agricultora & $12,8 \%$ \\
Auxiliar de Produção & $10,2 \%$ \\
Costureira & $5,3 \%$ \\
Doméstica & $5,3 \%$ \\
Professora & $34,3 \%$ \\
Outros & \\
\hline Condição no Mercado de Trabalho & $58,8 \%$ \\
Assalariada & $35,3 \%$ \\
Autônoma & $5,9 \%$ \\
Outros & \\
\hline Conhecimento dos Direitos Trabalhistas & $52,9 \%$ \\
Sim & $47,1 \%$ \\
Não & \\
\hline Exposição à riscos laborais & $35,8 \%$ \\
Nenhum Risco & \\
\hline Houve troca de função durante a gestação & $41,7 \%$ \\
Sim & $57,5 \%$ \\
Não & \\
\hline Houve alteração de comportamento do empregador & $13,9 \%$ \\
Sim & $86,1 \%$ \\
\hline Não & \\
\hline Liberação para realizar pré natal & $99,5 \%$ \\
Sim & $0,5 \%$ \\
\hline Não & \\
\hline
\end{tabular}

Fonte: Autor

Em relação ao estilo de vida das gestantes, conforme podemos visualizar na tabela 3, a grande maioria das entrevistadas não apresentavam agravos à saúde. Contudo, quando questionadas sobre o uso de medicamentos, 20,9\% utilizam algum tipo. Em relação ao uso de drogas lícitas, o tabaco foi identificado em 4,8\% da amostra. 
Tabela 3: Hábitos de vida das gestantes

\begin{tabular}{|l|r|}
\hline \multicolumn{1}{|c|}{ Variável } & \multicolumn{1}{c|}{$\%$} \\
\hline Possui algum tipo de doença & \\
Nenhuma & $90,4 \%$ \\
Problemas Cardiovasculares & $3,7 \%$ \\
Outros & $5,9 \%$ \\
\hline Utiliza Medicamentos & \\
Sim & $20,9 \%$ \\
Não & $79,1 \%$ \\
\hline Hábito Tabágico & \\
Sim & $4,8 \%$ \\
Não & $95,2 \%$ \\
\hline
\end{tabular}

Fonte: Autor

As oficinas realizadas, uma em cada município, tiveram característica interdisciplinar, com a participação do curso do Direito, equipe PET, com acadêmicos de Fisioterapia, Educação Física, Enfermagem, Psicologia e Ciências Biológicas, além da equipe que compõe os serviços básicos de saúde. A abordagem jurídica do tema trouxe várias discussões e sanou as dúvidas das gestantes presentes, que por meio de um questionário de satisfação, relataram estar satisfeitas em participar das oficinas. Algumas das gestantes manifestaram interesse em procurar o Núcleo de Prática Jurídica da Universidade para receber uma orientação especializada e um parecer sobre os problemas enfrentados na gestação com o empregador.

\section{Discussão}

O mercado de trabalho no Brasil conta com a progressiva participação das mulheres no mercado de trabalho, com aumento expressivo desde a década de 1960. Esse fato tem sido associado com a diminuição da taxa de fecundidade entre as mulheres (Leone e Baltar, 2008).

Segundo dados do IBGE (2010), há dez anos, as gestantes engravidavam antes dos 24 anos, e em 2010, esse percentual caiu para 45\%, Esses dados relacionados com a diminuição da fecundidade foram observados em nosso estudo, visto que as gestantes estão engravidando tardiamente e com um número menor de gestações.

Estudos demonstram que a queda na taxa de fecundidade pode estar relacionada, entre outros fatores, ao aumento do controle dentro do casamento, generalização do controle de fecundidade dentro das regiões e grupos sociais mais pobres, transformações socioeconômicas, tais como o aumento da escolaridade, da posse de bens de consumo duráveis e da participação das mulheres no mercado de trabalho. Além disso, um conjunto de políticas governamentais gerou mudanças 
culturais de grande difusão espacial, provocando a institucionalização da demanda por uma regulação da fecundidade, tais como o crédito ao consumidor, de telecomunicações, de previdência social e de atenção à saúde (Carvalho e Brito, 2005).

O desenvolvimento da atividade agrícola no Estado de Santa Catarina, predominantemente no Norte, tem sido um dos pilares econômicos da região, devido a sua grande extensão rural. Embora a atividade agrícola esteja mais ligada ao gênero masculino, na presente pesquisa houve uma grande parcela das entrevistadas que desenvolve essa atividade.

Apesar de nosso estudo demonstrar que as gestantes com emprego formal, são liberadas pelo empregador para realizar o pré-natal, parte significativa informou que não há a adaptação ou mudança de sua função no período gestacional. Além desse aspecto, é importante considerar que a contratação de trabalhadoras assalariadas temporárias é parte da rotina do processo produtivo das atividades agropecuárias em todo o Brasil. $\mathrm{O}$ sistema judiciário é um dos fatores que contribuíram para o surgimento do trabalho temporário. O conjunto desses novos trabalhadores que surgiram com as transformações ocorridas no processo de produção agropecuária forma um segmento dentro do mercado de trabalho agrícola, que por vezes fica a mercê de direitos sociais (Staduto, Rocha Junior e Bitencourt, 2004). Apesar dessas dificuldades, nos últimos 30 anos, uma série de leis avançaram no sentido da cobertura social dos trabalhadores rurais, sejam eles assalariados ou autônomos, aproximando-os em termos de direitos sociais, dos trabalhadores urbanos (Brumer, 2002).

No que se refere às gestantes agricultoras (32,1\%), cabe apontar que historicamente o direito ao salário-maternidade foi alcançado graças às pressões exercidas pelos movimentos de mulheres trabalhadoras rurais junto aos parlamentares, sendo aprovado em agosto de 1993 e regulamentado um ano depois. Através deste benefício, quando têm um filho(a), as mulheres trabalhadoras rurais passam a receber um benefício equivalente a um salário-mínimo mensal, durante quatro meses (120 dias), benefício que, na Constituição de 1988, foi estendido de três para quatro meses para as trabalhadoras urbanas (Brumer, 2002). A autora reforça que quando comparado com o sistema previdenciário urbano, a previdência rural mantém algumas características, como a idade limite da aposentadoria e comprovação da forma e período de contribuição.

Cabe apontar que o processo de gestação está associado a ajustes fisiológicos e anatômicos, que acarretam acentuadas mudanças no organismo materno necessárias ao perfeito crescimento e desenvolvimento fetal. No entanto, essas mudanças afetam o funcionamento habitual dos diversos sistemas, sendo este, um processo de transformações e adaptações, que em algumas mulheres trazem consequências que podem resultar em dor e limitações em suas atividades diárias (Almeida e Souza, 2002). Quando esses desconfortos se somam a algumas atividades de trabalho ou não adaptação, podem acarretar riscos que comprometem a saúde da trabalhadora gestante. 
Esse fato pode se prorrogar além da gravidez, afastando a trabalhadora de suas atividades, não apenas no período gestacional, mas após o parto ou até mesmo invalidando-a para atividades produtivas (Pinheiro e Estarque, 2000).

As modificações corporais impedem a gestante de exercer determinadas atividades, principalmente as que necessitam de rapidez, concentração, precisão, transporte de cargas, entre outras (Burroughs, 1995). Portanto, faz-se necessário que o empregador seja informado sobre seus deveres e as legislações trabalhistas sejam cumpridas, afim de assegurar a saúde do binômio mãe/bebê.

No Brasil, no ano de 2011, foi instituído no âmbito do Sistema Único de Saúde o programa 'Rede Cegonha', que consiste em cuidados que visam assegurar à mulher o direito ao planejamento reprodutivo e à atenção humanizada na gravidez, ao parto e ao puerpério, bem como à criança o direito ao nascimento seguro e ao crescimento e ao desenvolvimento saudáveis (Brasil, 2011). Ela objetiva fomentar a implementação de um novo modelo de atenção à saúde da mulher e da criança, com foco na atenção ao parto, nascimento, crescimento e desenvolvimento da criança de zero aos vinte e quatro meses, acesso, acolhimento e resolutividade dos serviços, bem como redução à mortalidade materna e infantil, com ênfase no componente neonatal.

Quanto ao pré-natal, as gestantes pesquisadas informaram serem liberadas pelo empregador para realizá-lo. Além de ser um direito, a assistência ao pré-natal foi fortalecida com a implementação da 'Rede Cegonha', que delineou estratégias para a sua realização na Unidade Básica de Saúde (UBS), com captação precoce da gestante e qualificação da atenção, acolhimento às intercorrências na gestação com avaliação e classificação de risco e vulnerabilidade, acesso ao pré-natal de alto risco em tempo oportuno, realização dos exames de risco habitual e de alto risco, acesso aos resultados em tempo oportuno, vinculação da gestante desde o pré-natal ao local em que será realizado o parto, implementação de estratégias de comunicação social e programas educativos relacionados à saúde sexual e reprodutiva e apoio às gestantes nos deslocamentos para as consultas e para o local em que será realizado o parto.

Na região Sul do Brasil, no ano de 2013, de acordo com dados do Ministério da Saúde, $74,30 \%$ das gestantes havia realizado 7 ou mais consultas de pré-natal (Brasil, 2014).

Com relação a escolaridade, os dados mostram que apenas 14,4\% das gestantes entrevistadas, possuem Ensino Superior completo. Araújo e Tanaka (2007) descreveu que condições educacionais baixas são fatores associados à gestação de alto risco e ao maior número de gestações. Embora as gestantes pesquisadas tivessem um baixo nível de escolaridade, a quantidade de filhos foi de apenas $1,7 \%$ por mulher. Além disso, o autoconhecimento do corpo pela mulher e as alterações dele provenientes, podem também estar associados ao nível de escolaridade do indivíduo e aos valores culturais (Salimena, Coelho, Melo, Greco e Almeida, 2012), assim como a compreensão sobre seus direitos. 
$\mathrm{Na}$ análise do estilo de vida da gestante, um dado que nos chama a atenção é o uso de medicamentos. Cerca de $20 \%$ da amostra faz uso de algum tipo de medicamento. Contudo, esses medicamentos podem fazer parte da assistência pré-natal, como salienta Carmo (2004) em seu estudo, em que 44,7\% das gestantes tiveram prescrição medicamentosa nas consultas pré-natal. Esse dado pode ser interpretado como o maior cuidado das gestantes em relação à sua saúde, bem como ao maior acesso ao sistema de saúde, ou como um problema, ao considerarmos os apontamentos de Brum, Pereira, Felicetti e Silveira (2011), de que a medicalização da gestação associada ao uso irracional de medicamentos constitui um comportamento de alto risco, uma vez que nenhum medicamento é isento de toxicidade à mãe ou ao feto e deve ser considerado um problema de saúde pública.

Com relação ao hábito tabágico, observou- se haver entre as gestantes um baixo consumo dessa substância, que é considerada uma das principais causas evitáveis de morbilidade e mortalidade em países desenvolvidos, assim como um dos maiores problemas de saúde pública mundial, com impacto sobre o desenvolvimento gestacional saudável (Lin e outros, 2009).

As gestantes quando questionadas sobre seus direitos frente a sua nova condição, relatam conhecê-los $(52,9 \%)$. Este dado isoladamente traduz um bom entendimento sobre os seus direitos, contudo, ainda temos $47,1 \%$ das entrevistadas que os desconhecem. As trabalhadoras gestantes têm direitos trabalhistas claros, estabelecidos na Constituição Federal e na CLT, com o objetivo de assegurar a proteção do emprego e a garantia da saúde da mulher e da criança. Entre os principais direitos da funcionária no período da gravidez estão a estabilidade no emprego, da concepção até cinco meses após o parto, e a licença-maternidade remunerada de 120 dias.

Para Lopes (2006), em um contexto histórico dos direitos das mulheres, a legislação de proteção ao trabalho da mulher voltou-se, em um primeiro momento, para as relações de trabalho originadas em razão da Revolução Industrial, muito embora as mulheres jamais tenham deixado de reivindicar seus direitos, acredita-se que muitas dessas reivindicações a favor de mulheres, foram realizadas por homens, preocupados com o desemprego.

Com a promulgação da Constituição Federal do Brasil de 1988, no âmbito trabalhista, foram muitas as alterações legislativas, tais como o abandono do princípio de 'proteção da mulher', mediante revogação de normas falsamente protetivas, redimensionamento das normas de proteção à maternidade no âmbito trabalhista e previdenciário, instituição de normas de combate à discriminação e meios de assegurar a igualdade (Lopes, 2006).

Considerando aqui um estudo realizado por Oliveira (2001), chama a atenção entre as gestantes trabalhadoras, o medo de interromper a gravidez devido ao trabalho, ou mesmo o receio de que o fato de estarem grávidas faça com que modifiquem o seu trabalho. Mesmo as mulheres que estão inseridas no mercado formal de trabalho e que 
são respaldadas legalmente, não se sentem à vontade para garanti-lo. A legislação em relação ao direito reprodutivo não garante, de fato, o acesso aos acompanhamentos ambulatoriais de pré-natais, que enquanto um direito reprodutivo, está distanciado da realidade das mulheres. $\mathrm{Na}$ faceta informal, os direitos reprodutivos não são contemplados para as mulheres. Há um distanciamento, já que os direitos reprodutivos como algo mais complexo que a legislação - trata das diversas relações de trabalho. Ressalta-se que a conciliação entre as obrigações familiares, domésticas e o exercício profissional traduz-se num sofrimento que pode ser traduzido em implicações danosas para a saúde.

Pode-se observar ainda, que a participação da gestante em atividades de educação em saúde, promovidas pelos serviços de saúde que envolvem essa temática, é baixa, pois somente 70 entrevistadas participaram da oficina, cujo objetivo principal era trazer informações sobre seus direitos.

Nesse contexto, alguns autores afirmam que é necessário, assumir o processo da promoção da saúde como uma mudança de enfoque, conceitos e formas de atuar, com o intuito de vencer a fragmentação e aproximar a cultura científica que ainda permanece distante dos sujeitos para que elas caminhem na mesma direção, progredindo para a sustentabilidade (Bydlowski, Westphal e Pereira, 2004). Promover saúde envolve o compromisso político e técnico de enfatizar, como foco de intervenção, os fatores determinantes do processo saúde-doença (Buss, 2000). A mediação intersetorial é fundamental para o exercício da cidadania e do controle social.

Esta pesquisa colaborou para referenciar que no grupo PET fosse observada necessidade de integrar profissionais de áreas distintas da saúde, como foi o curso de Direito. O fórum de discussão, previsto nas oficinas, foi além do aspecto saúde e trabalho para abordar a inclusão e cidadania, questões muitas vezes omitidas por quem está envolvido no processo de assistência.

\section{Conclusão}

Esta pesquisa possibilitou identificar o perfil das gestantes trabalhadoras do Planalto Norte catarinense e o seu conhecimento sobre seus direitos trabalhistas. O baixo índice de tabagismo e ausência de agravos à saúde refletem o melhor cuidado da mulher com a saúde nessa fase. As entrevistadas demonstraram conhecimento sobre seus direitos trabalhistas e a manutenção das atividades laborais com o apoio dos empregadores.

A não totalidade na participação das oficinas pôde apontar desigualdades sutis entre os trabalhos, as trabalhadoras e sua situação de gênero e gestação que não puderam ser alcançadas pela metodologia escolhida para a coleta de dados desta pesquisa. 
Esta pesquisa ampliou as possibilidades de diálogo entre IES e serviço de saúde. Entende-se que a atividade de extensão, no presente trabalho realizado por meio de oficinas baseada na realidade pesquisada, é uma importante ferramenta na aproximação entre serviços de saúde e Universidade, além de permitir a integração de outros cursos que não fazem parte direta da equipe de saúde com vistas à interdisciplinaridade.

\section{Referências}

Almeida, L. e Souza, E. (2002). Alterações do sistema músculo-esquelético e suas implicações. In E. Souza. Fisioterapia aplicada à obstetrícia - Aspectos de ginecologia e neonatologia. $3^{\mathrm{a}} \mathrm{ed}$. (pp .33-40). Rio de Janeiro: Medsi.

Anderson, J. (1994). La feminización de la pobreza en América Latina. Lima: Red Entre Mujeres: Diálogo Sur-Norte.

Araújo, B. F. e Tanaka, A. C. d'A. (2007). Fatores de risco associados ao nascimento de recém-nascidos de muito baixo peso em uma população de baixa renda. Cadernos de Saúde Pública, 23(12), 2869-2877. Recuperado em 16 de janeiro de 2014, de https://dx.doi.org/10.1590/S0102-311X2007001200008.

Brasil. Ministério da Saúde (2011) Pet-Saúde. Brasília: Ministério da Saúde. Recuperado em 10 setembro de 2014, de http://www.prosaude.org/.

Brasil. Ministério da Saúde (2012). Política Nacional de Saúde do Trabalhador e da Trabalhadora. Brasília: Ministério da Saúde. Recuperado em 15 setembro de 2014, http://bvsms.saude.gov.br/bvs/saudelegis/gm/2012/prt1823_23_08_2012.html.

Brasil. Ministério da Saúde (2011). Portaria n. 1459 de 24 de junho de 2011. Brasília: Ministério da Saúde. Recuperado em 15 setembro de 2014, de http://bvsms.saude.gov.br/bvs/saudelegis/gm/2011/prt1459_24_06_2011.html.

Brasil. Ministério da Saúde (2005). Consultas de pré-natal. Brasília: Ministério da Saúde - Datasus. Recuperado em 04 de janeiro de 2015, de http://tabnet.datasus.gov.br/cgi/tabcgi.exe?sinasc/cnv/nvuf.def.

Brasil. Ministério da Saúde (2014). Saúde Brasil 2014: Uma análise da saúde e das doenças transmissíveis relacionadas à pobreza. Brasília: Ministério da Saúde. Secretaria de Vigilância em Saúde. Departamento de Análise de Situação em Saúde. Recuperado em 10 de janeiro de 2015, de http://bvsms.saude.gov.br/bvs/publicacoes/saude_brasil_2013_analise_situacao_ saude.pdf.

Brito, M. R. F. (1996). Um estudo sobre as Atitudes em Relação à Matemática em Estudantes de $1^{\circ}$ e $2^{\circ}$ graus. Tese de Livre Docência. Campinas: Unicamp.

Brito, J. C. e D'Acri, V. (1991). Referencial de análise para a estudo da relação trabalho, mulher e saúde. Cadernos de Saúde Pública, 7(2), 201-214. Recuperado em 27 
de fevereiro de 2014, de https://dx.doi.org/10.1590/S0102311X1991000200006.

Brum, L. F. S., Pereira, P., Felicetti, L. L. e Silveira, R. D. (2011). Utilização de medicamentos por gestantes usuárias do Sistema Único de Saúde no município de Santa Rosa (RS, Brasil). Ciência \& Saúde Coletiva, 16(5), 24352442. Recuperado em 12 de janeiro de 2015, de https://dx.doi.org/10.1590/S1413-81232011000500012.

Brumer, A. (2002). Previdência social rural e gênero. Sociologias, (7), 50-81. Recuperado em 20 de setembro de 2014, de http://www.scielo.br/pdf/soc/n7/a03n7.pdf.

Burroughs, A. (1995). Uma Introdução a Enfermagem Materna. $8^{\mathrm{a}}$ ed. Porto Alegre: Artmed.

Buss, P. M. (2000). Promoção da saúde e qualidade de vida. Ciência \& Saúde Coletiva, 5(1), 163-177. Recuperado em 27 de janeiro de 2014, de https://dx.doi.org/10.1590/S1413-81232000000100014

Bydlowski, C. R., Westphal, M. F. e Pereira, I. M. T. B. (2004). Promoção da saúde. Porque sim e porque ainda não! Saúde e Sociedade, 13(1), 14-24. Recuperado em 1 de fevereiro de 2014, de https://dx.doi.org/10.1590/S010412902004000100003 .

Carmo, T. A. e Nitrini, S. M. O. O. (2004). Prescrições de medicamentos para gestantes: um estudo farmacoepidemiológico. Cadernos de Saúde Pública, 20(4), 10041013. Recuperado em 27 de janeiro de 2015, de https://dx.doi.org/10.1590/S0102-311X2004000400015.

Carvalho, J. A. M. e Brito, F. (2005). A demografia brasileira e o declínio da fecundidade no Brasil: contribuições, equívocos e silêncios. Revista Brasileira de Estudos de População, 22(2), 351-369. Recuperado em 27 de janeiro de 2015, de https://dx.doi.org/10.1590/S0102-30982005000200011.

Dejours, C. (1992). A loucura do trabalho: Estudo de psicopatologia do trabalho. São Paulo: Cortez/Oboré.

Godoy, M. B., Gomes, F. A., Stefanello, J.,Monteiro, J. C. S. e Nakano, A. M. S.(2011). Situação trabalhista da mulher no ciclo grávido-puerperal. Investigación y Educación en Enfermería, 29(1), 47-53.

International Labour Office (2012). Global estimate of forced labourExecutive summary. International Geneva: Labour Office. Recuperado em 26 de dezembro de 2013, de http://www.ilo.org/wcmsp5/groups/public/@ed_norm/@declaration/documents/ publication/wcms_181953.pdf.

Leone, E. T. e Baltar, P. (2008). A mulher na recuperação recente do mercado de trabalho brasileiro. Revista Brasileira de Estudos de População, 25(2), 233249. Recuperado em 18 de fevereiro de 2015, de https://dx.doi.org/10.1590/S0102-30982008000200003. 
Lin ,Y. H., Tsai, E. M., Chan, T. F., Chou, F. H. e Lin Y. L. (2009). Health promoting lifestyles and related factors in pregnant women. Chang Gung medical journal. 32(6). 650-61.

Lopes, C. M. S. (2006). Direito do trabalho da mulher: da proteção à promoção. Cadernos Pagu, (26), 405-430. Recuperado em 1 de fevereiro de 2015, de https://dx.doi.org/10.1590/S0104-83332006000100016.

Mitre, S. M. e outros (2008). Metodologias ativas de ensino-aprendizagem na formação profissional em saúde: debates atuais. Ciência \& Saúde Coletiva, 13(Suppl. 2), 2133-2144. Recuperado em 14 de fevereiro de 2016, de https://dx.doi.org/10.1590/S1413-81232008000900018.

Oliveira, A. C. O. (2001). Gênero, saúde reprodutiva e trabalho: formas subjetivas de viver e resistir às condições de trabalho. Dissertação de mestrado em Saúde Pública Fundação Oswaldo Cruz, Rio de Janeiro.

Pinheiro, M. e Estarque. M. (2000). Estresse. Launched: Geocities. Recuperado em 10 de agosto de 2014, de http://www.geocities.com/hotSprings/Oasis/84/8/estresse. html.

Souza, A. I., Filho, M. B. e Ferreira, L. O. C. (2002). Alterações hematológicas e gravidez. Revista Brasileira de Hematologia e Hemoterapia, 24(1), 2936. Recuperado em 26 de março de 2014, de https://dx.doi.org/10.1590/S151684842002000100006 .

Salimena, A. M. O., Coelho, A. C. P., Melo, M. C. S. C., Greco, R. M. e Almeida, M. I. G. (2012). Conhecimentos e atitudes de mulheres varredoras de rua sobre o cuidado ginecológico. Texto \& Contexto - Enfermagem, 21(1), 4351. Recuperado em 28 de novembro de 2014, de https://dx.doi.org/10.1590/S0104-07072012000100005.

Staduto, J., A. R., Rocha Junior, W, F. e Bitencourt, M. B. (2004). Contratos no mercado de trabalho agrícola: o caso das cooperativas de trabalhadores rurais. Revista de Economia e Sociologia Rural, 42(4), 637-661.Recuperado em 6 de fevereiro de 2015, de https://dx.doi.org/10.1590/S010320032004000400006.

Data de recebimento: $16 / 02 / 2015$

Data de revisão: $22 / 05 / 2015$

Data do aceite: 06/07/2016 